\title{
Experiment based comparative analysis of stator current controllers using predictive current control and proportional integral control for induction motors
}

\author{
Vo Thanh $\mathrm{Ha}^{1}$, Tran Trong Minh${ }^{2}$, Nguyen Tung $\mathrm{Lam}^{3}$, Nguyen Hong Quang \\ ${ }^{1}$ University of Transport and Communications, Vietnam \\ ${ }^{2,3}$ Hanoi University of Science and Technology, Vietnam \\ ${ }^{4}$ Thai Nguyen University of Technology, Vietnam
}

\begin{tabular}{|c|c|}
\hline Article Info & ABSTRACT \\
\hline Article history: & The stator current control loop plays an important role in ensuring the quality \\
\hline Received Dec 19, 2019 & of electric drives interm of producing fast and adequate required torque. \\
\hline Revised Feb 22, 2020 & $\begin{array}{l}\text { When the current controller provides ideal responses, speed control } \\
\text { design subsequently is in charge of improving the system performances. }\end{array}$ \\
\hline Accepted Apr 1, 2020 & $\begin{array}{l}\text { Classical PID control is commonly used in current loop design, this paper } \\
\text { presents the comparative analysis of current stator controller using }\end{array}$ \\
\hline Keywords: & field-oriented control-based induction motor drives, with rigidly coupled \\
\hline $\begin{array}{l}\text { FCS-MPC } \\
\text { Field oriented control (FOC) }\end{array}$ & $\begin{array}{l}\text { loads. The experimental results show system responses with PID and PCC. } \\
\text { Informative experiment-based analysis provides primary guidance in } \\
\text { selection between the two controls. }\end{array}$ \\
\hline
\end{tabular}

This is an open access article under the CC BY-SA license.

PCC-MPC

Voltage source inverter

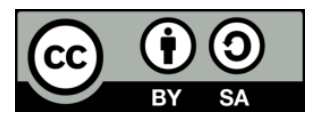

\section{Corresponding Author:}

Nguyen Hong Quang,

Thai Nguyen University of Technology,

666, 3/2 Street, Tich Luong Ward, Thai Nguyen City-Thai Nguyen Province, Vietnam.

Email: quang.nguyenhong@ tnut.edu.vn

\section{INTRODUCTION}

Due to the importance of electrical drive system in modern industrial applications, numerous studies have been conducted on the structure of the system. One of the most common frequency control methods for the induction motor drive proposed is scalar control, which is considered as inadequate in high quality motion applications [1]. Proven to possess more advantages than scalar control method for speed control of the induction motor, vector control methods find their place in various motion control systems [2, 3].

Well-known for its simplicity, direct torque control (DTC) regulates motor flux and torque in a direct way. However, DTC control possesses a major difficulty during low speed ranges. Many researches are conducted to provide a solution to the existing issues of the coupling between flux and torque forming components of the stator current vector [4]. The field-oriented control (FOC) scheme is developed based on successfully controlling the decoupled current components using closed-loop control. The FOC structure for the induction motor includes stator currents loop with fast time constants and outer loops such as speed and position control loops with greater time constant $[3,5]$. With the FOC control structure, many linear or nonlinear controls are implemented [6-13]. The classical PI controller can only be effective around the operating point, when operating in a wide range the system performance can be degraded [14]. Nonlinear methods, with more computational requirements, exhibit its ability in a wide operating range. Several control schemes used in FOC based induction motor drives can be found in [3, 5].

Recently, the application of model predictive control (MPC) in electric drives attracts many researchers. The basic principle of MPC is to calculate the optimum values for actuating variables based 
on mathematical model of the system, the historic control actions and the optimization of cost function over a receding prediction horizon. MPC has many advantages such as intuitive concept and simple implementation [15]. MPC can be classified into two categories: continuous MPC and finite set control MPC (FSC-MPC). Continuous MPC requires complex modulations and its algorithm is complicated. Because of its easy realization of nonlinear control and constraints (e.g., over current protection, switching loss minimization, etc.) inclusion capability, FSC-MPC attracts research attentions and efforts. FSC-MPC does not need any continuous actuating variable or modulator. In FSC-MPC, the model of inverter is directly taken into consideration in the controller [16]. Every feasible switching vector is considered in the calculation of the cost function. The one minimizing the cost function is selected as the optimal output. FSC-MPC (for simplicity, hereafter referred to as MPC) has been successfully used in almost all kinds of applications in power electronics, including DC-DC, DC-AC, AC-DC and AC-AC converters [17-19]. As for electrical drives systems, MPC has been deeply investigated for AC machines [20-22]. MPC can also be used for sensorless drive systems with achieved good performances [23, 24]. Different prediction horizon based MPC methods have been considered. With longer prediction steps, better performances are expected to be obtained. However, problems of time consuming calculation must be solved.

This paper presents the design, analysis and comparison of the stator currents responses, by using PI controller (PI-FOC) and predictive current control (PCC-FOC). When the stator current regulator via the cost function in PCC-FOC, we can achieve objective features in the closed loop responses [3, 5]. When implementing the stator voltage control satisfies the requirement of "fast-accuracy-decoupling" properties in current response, the induction motor can be considered as fed by a controllable current source inverter, which leads to order reduction of induction motor drive system from 4th to 2 nd order [25]. Thus, it is essential to produce fast, accurate current (torque) with small ripple and overshoot.

\section{MODEL OF INDUCTION MOTOR AND MODELS OF VOLTAGE SOURCE INVERTER}

\subsection{Mathematic model of induction machine}

The induction motor model in the $d-q$ reference frame was obtained [14]:

$$
\left\{\begin{array}{l}
\frac{d i_{s d}}{d t}=-\frac{1}{T_{\sigma}^{\prime}} i_{s d}+\omega_{s} i_{s q}+\frac{k_{r}}{r_{\sigma} T_{\sigma}^{\prime} T_{r}} \psi_{r d}+\frac{1}{r_{\sigma} T_{\sigma}^{\prime}} u_{s d} \\
\frac{d i_{s q}}{d t}=-\omega_{s} i_{s d}-\frac{1}{T_{\sigma}^{\prime}} i_{s q}-\frac{k_{r}}{r_{\sigma} T_{\sigma r}^{\prime}} \omega \psi_{r d}+\frac{1}{r_{\sigma} T_{\sigma}^{\prime}} u_{s q} \\
\frac{d \psi_{r d}}{d t}=\frac{L_{m}}{T_{r}} i_{s d}-\frac{1}{T_{r}} \psi_{r d} \\
\frac{d \omega}{d t}=\frac{3}{2} \frac{z_{p}^{2} L_{m}}{L_{r} J} \psi_{r d} i_{s q}-\frac{z_{p} T_{L}}{J}
\end{array}\right.
$$

With parameters used in the model shown as:

$$
\begin{aligned}
& \sigma=1-\frac{L_{m}^{2}}{L_{s} L_{r}}: \text { leakage factor; } T_{s}=\frac{L_{s}}{R_{s}}: \text { stator time constant } \\
& T_{r}=\frac{L_{r}}{R_{r}}: \text { rotor time constant } \\
& \text { Coefficients: } k_{r}=\frac{L_{m}}{L_{r}} ; r_{\sigma}=R_{s}+R_{r} k_{r}^{2} ; T_{\sigma}^{\prime}=\frac{\sigma L_{\sigma}}{r_{\sigma}} \\
& \omega_{s}=\omega+\frac{L_{m}}{T_{r}} \frac{i_{s d}}{\psi_{r d}}: \text { slip estimation }
\end{aligned}
$$

Where: $\omega \quad$ : Mechanical rotor speed

$z_{p} \quad:$ Number of pole pairs

$J \quad$ : Torque of inertia

$T_{L} \quad$ : Torque load

$\psi_{r d} \quad:$ Rotor flux

$L_{m}, L_{r}, L_{s}:$ Mutual, rotor, stator inductance 


\subsection{Mathematic model of inverter}

A two-level three-phase voltage source inverter (VSI) serves as the power converter in this work. Its topology and all feasible voltage vectors are displayed in Figure 1. Switching state $\mathbf{S}$ is in the form of a vector sum:

$$
S_{i}, \overline{S_{i}}=1,0 \mathbf{S}=\frac{2}{3}\left(S_{a}+\mathbf{a} S_{b}+\mathbf{a}^{2} S_{c}\right)
$$

in which $a=e^{j 2 \pi 3}$, shows the on, off states of the upper, lower switches of lag $i$, with $i=a, b, c$. The output voltage vector $\boldsymbol{v}$ is of the same amplitude of DC link voltage and calculated from switching state $\boldsymbol{S}$ as:

$$
\mathbf{v}=V_{d c} \mathbf{S}
$$

\section{EVALUATION OF PI CURRENT CONTROLLER IN FOC STRUCTURE}

PI control for stator current in IM is well established, hence PI control in $d$ and $q$ stator currents are in the following forms without further explanation [14, 23]:

$$
\begin{aligned}
& u_{s d}=K_{c}^{d}\left(i_{s d}^{*}-i_{s d}\right)+\left(\frac{K_{c}^{d}}{T_{I}^{d}} \int\left(i_{s d}^{*}-i_{s d}\right)\right) d t-\frac{k_{r}}{T_{r}} \psi_{r d}-T_{\sigma}^{\prime} r_{\sigma} \omega_{s} i_{s q} \\
& u_{s q}=K_{c}^{q}\left(i_{s q}^{*}-i_{s q}\right)+\left(\frac{K_{c}^{q}}{T_{I}^{q}} \int\left(i_{s q}^{*}-i_{s q}\right)\right) d t+r_{\sigma} T_{\sigma}^{\prime} \omega_{s} i_{s d}+k_{r} \omega \psi_{r d}
\end{aligned}
$$

From equation of PI stator current controllers using FOC of an induction machine with PI controller as shown in Figure 1.

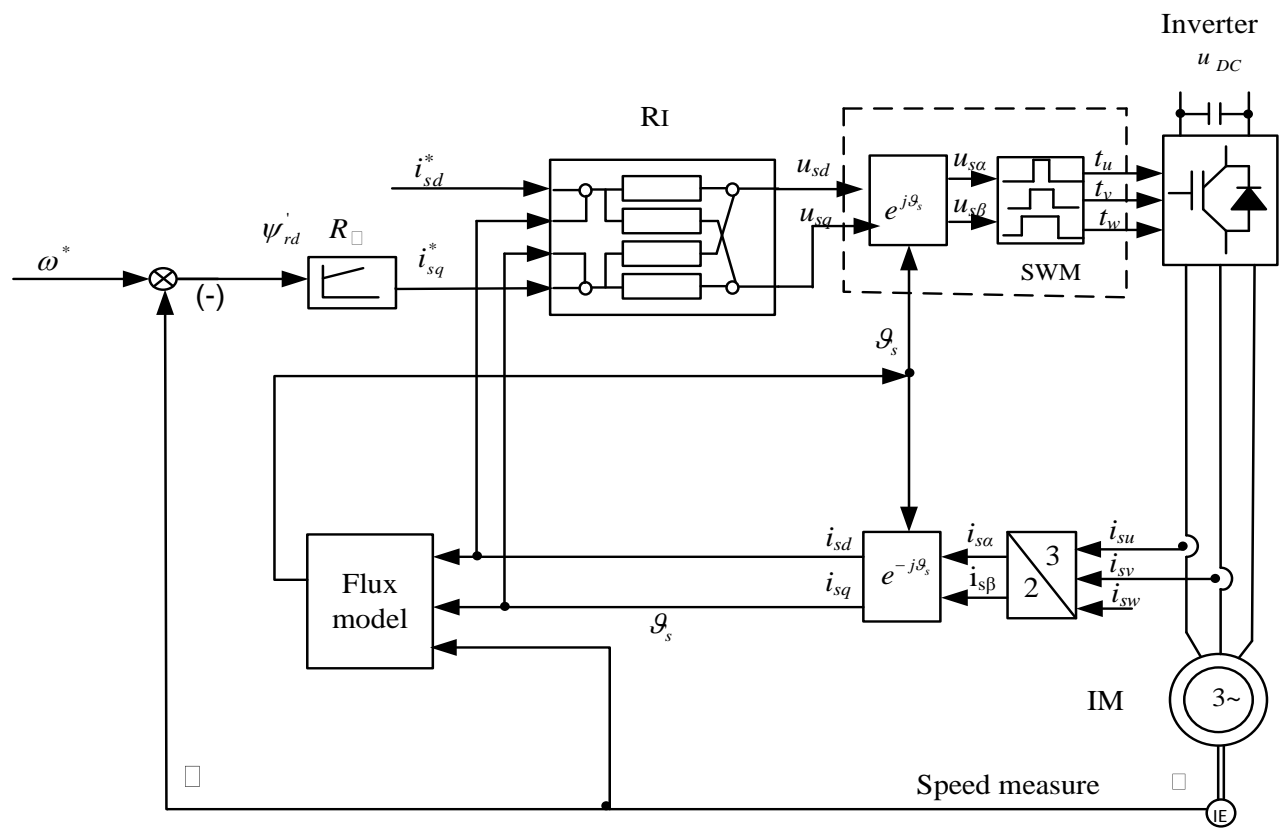

Figure 1. Block structure of the PI stator current controllers

\section{EVALUATION OF PREDICTIVE CURRENT CONTROLLER (PCC) IN FOC STRUCTURE}

The model predictive control structure for FOC is based on a flux rotor calculation of the IM fed by a two-level voltage source inverter. Assuming that the measured signals such as speed motor $\omega$, stator currents $i_{s \alpha}, i_{s \beta}$ are available. Based on previous studies $[14,16]$, the estimated stator currents are expressed by equation: 


$$
\begin{aligned}
& i_{s \alpha}(k+1)=\phi_{11} i_{s \alpha}(k)+h_{11} u_{s \alpha}(k)+\phi_{13} \psi^{\prime}{ }_{r \alpha}(k)+\phi_{14} \psi^{\prime}{ }_{r \beta}(k) \\
& i_{s \beta}(k+1)=\phi_{11} i_{s \beta}(k)+h_{11} u_{s \beta}(k)+\phi_{13} \psi^{\prime}{ }_{r \beta}(k)-\phi_{14} \psi^{\prime}{ }_{r \alpha}(k)
\end{aligned}
$$

where: $\phi_{11}=1-\frac{T}{\sigma}\left(\frac{1}{T_{s}}+\frac{1-\sigma}{T_{r}}\right) ; \phi_{13}=\frac{1-\sigma}{\sigma} \frac{T}{T_{r}} ; \phi_{14}=\frac{1-\sigma}{\sigma} \omega T ; h_{11}=\frac{T}{\sigma L_{s}}$

The motor flux can be estimated as:

$$
\begin{aligned}
& \psi_{r \alpha}^{\prime}=\frac{T}{T_{r}} i_{s \alpha}(k-1)+\left(1-\frac{T}{T_{r}}\right) \psi_{r \beta}^{\prime}(k-1)-\omega T \psi_{r \beta}^{\prime}(k-1) \\
& \psi_{r \beta}^{\prime}=\frac{T}{T_{r}} i_{s \beta}(k-1)+\left(1-\frac{T}{T_{r}}\right) \psi_{r \alpha}^{\prime}(k-1)-\omega T \psi_{r \beta}^{\prime}(k-1)
\end{aligned}
$$

According to (6), (7) flux is calculated through the measured $i_{\beta}(k+1) i_{\alpha}, i_{\beta} \psi_{r \alpha}^{\prime}, \psi_{r \beta}^{\prime} u_{\alpha}(k), u_{\beta}(k) i_{\alpha}(k), i_{\beta}(k)$ value of the stator current and speed motor $\omega$ and flux rotor from in the previous step. With the flux calculated according to (6), (7) line stator model is shown to be the stator model (5) in step $(\mathrm{k}+1)$ with the input control voltage and current of stator measured at time $k$.

The model predictive control method calculates cost functions for all sectors, since it is the method that obtains the reference voltage by selecting the minimum value, it has the advantage of selecting the most optimal voltage vector which include several limitations and nonlinear characteristics. When actualizing the basic MPC algorithm of the three-level inverter, the voltage vector is selected by calculating 8 cost functions. However, since the selected reference voltage vector is applied for one period, it has a drawback of having severely large ripples of torque and flux compare to the calculation. The predictive control scheme and algorithm for induction motor control are presented in Figure 2 respectively. The cost function in the predictive control of IM with delay compensation is presented as:

$$
g=\left|\mathrm{i}^{*}[k+1]-\mathrm{i}[k+1]\right|
$$

where: $\left|\mathrm{i}^{*}[k+1] ; \mathrm{i}[k+1]\right|$ is the value of the applied current vector and the current vector on the load at the time $(\mathrm{k}+1)$ predicted by $(5)$. With a small sampling period, we can approximate the amount of $i^{*}[k+1] \approx i[k]$. From there, rewrite (8) the cost function in the $\alpha \beta$ coordinate system:

$$
g=\left|i_{\alpha}^{*}(k)-i_{\alpha}(k+1)\right|+\left|i_{\beta}^{*}(k)-i_{\beta}(k+1)\right|
$$

where: $i_{\alpha}(k+1)$ and are the real of the predicted stator current phasor; $i_{\alpha}^{*}(k), i_{\beta}^{*}(k)$ are the respective desired parts of the current space phasor reference. With the two-level inverter diagram we have eight switching states of three valve branches, meaning that in each cycle of time sample $\mathrm{T}$ we perform eight calculations and the target function (9), will find one the eight most appropriate states to make the rectifier open and close. The algorithm performs the selection of the voltage vector for less than algorithm 1 . Predicted stator current controller combined flux estimation model and PCC model fed by a two level voltage source inverter as shown in Figure 2.

Algorithm 1. Voltage vector selection algorithm

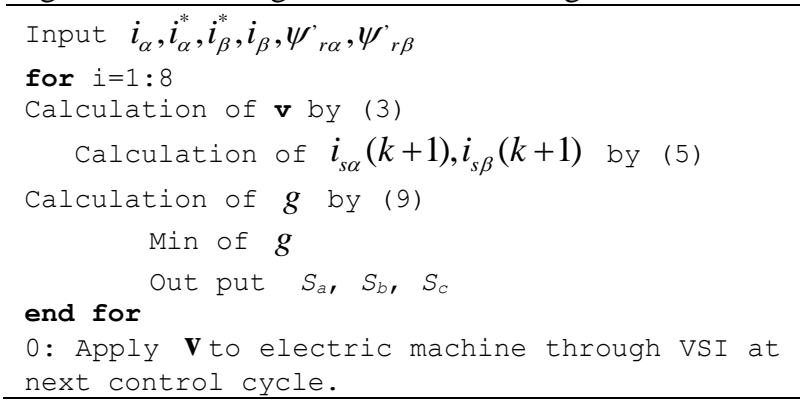

Experiment based comparative analysis of stator current controllers using predictive ... (Vo Thanh Ha) 


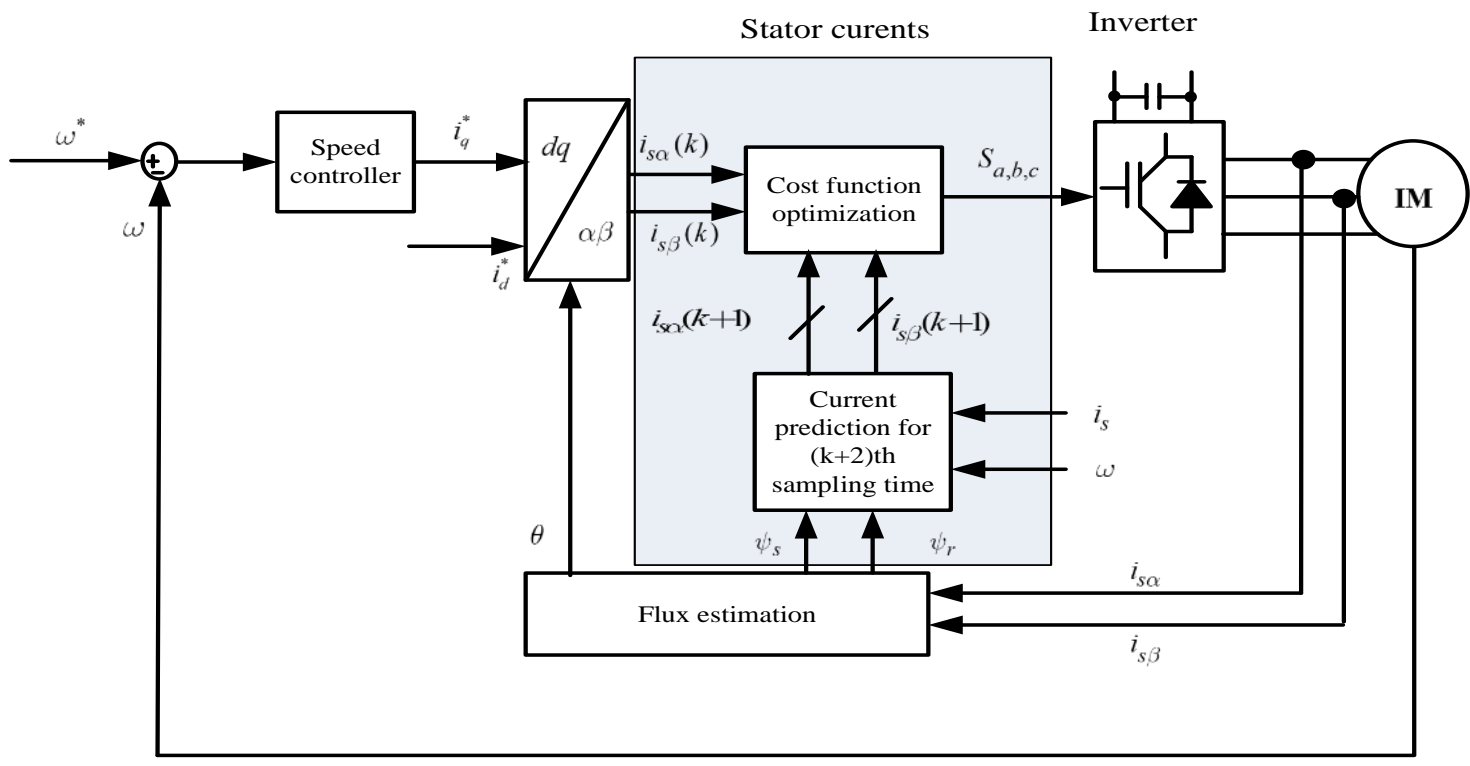

Figure 2. Block structure of the stator current controllers with predictive current controller

\section{EXPERIMENTAL RESULTS}

The stator current controllers using PI-FOC and PCC-FOC with speed controller is PI controller, where the rotor flux $\psi_{r d}$ is established and has a constant value in sections 3 and 4 verified through experimental. Experiments are conducted on an IM machine with parameters in Table 1. Test bench is shown in Figure 3. The stator current controllers using PI-FOC and PCC-FOC with speed controller are PI controller, where the rotor flux $\psi_{r d}$ is established and has a constant value in sections 3 and 4 verified through experimental. Model parameters are given in the Table 1.

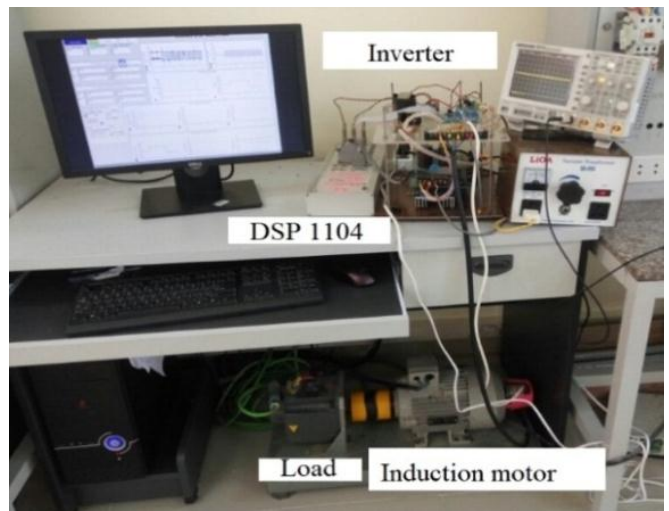

Figure 3. Photo of experimental setup

Table 1. Model parameters of induction motor

\begin{tabular}{lll}
\hline Parameters & Nomenclature & Value \\
\hline Rated power & $\mathrm{P}_{\text {nom }}$ & $1.5 \mathrm{~kW}$ \\
Rated Torque & $\mathrm{n}_{\text {nom }}$ & $2880 \mathrm{vg} / \mathrm{ph}$ \\
Rated phase current & $\mathrm{I}_{\text {nom }}$ & $4.7 \mathrm{~A}_{\mathrm{RMS}}$ \\
Number of pole pairs & $\mathrm{Z}_{\mathrm{p}}$ & 1 \\
Rotor resistance & $\mathrm{R}_{\mathrm{r}}$ & $0.42 \Omega$ \\
Stator resistance & $\mathrm{R}_{\mathrm{s}}$ & $0.37 \Omega$ \\
Rotor inductance & $\mathrm{L}_{\mathrm{r}}$ & $34.25 \mathrm{mH}$ \\
Stator inductance & $\mathrm{L}_{\mathrm{s}}$ & $34.41 \mathrm{mH}$ \\
Mutual inductance & $\mathrm{L}_{\mathrm{m}}$ & $33.1 \mathrm{mH}$ \\
Torque of inertia & $\mathrm{J}$ & $0.001 \mathrm{kgm}$ \\
Frequency modulation & $\mathrm{f}_{\mathrm{pwm}}$ & $5 \mathrm{kHz}$ \\
\hline
\end{tabular}


Experimental procedure: at $\mathrm{t}=0$ (s) create magnetic current; $\mathrm{t}=4$ (s) speed up to $20 \mathrm{rad} / \mathrm{s} ; \mathrm{t}=8.8$ (s) speed down to $-20 \mathrm{rad} / \mathrm{s}$. In the test, a sudden torque with rated value of $1.5 \mathrm{Nm}$ is applied on the motor shaft. The results of the simulation of stator current controllers using PI-FOC and PCC-FOC are shown in Figure 4.

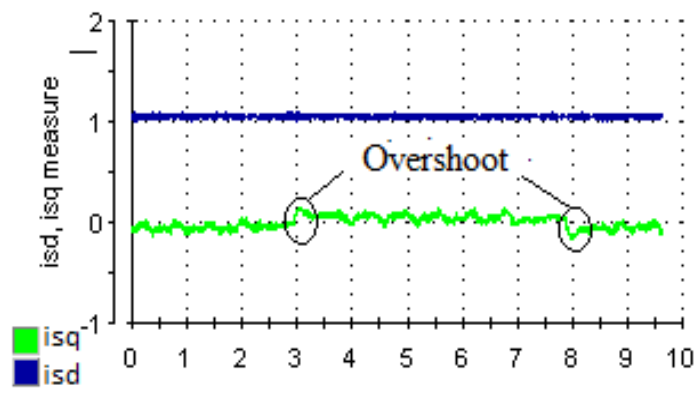

(a)

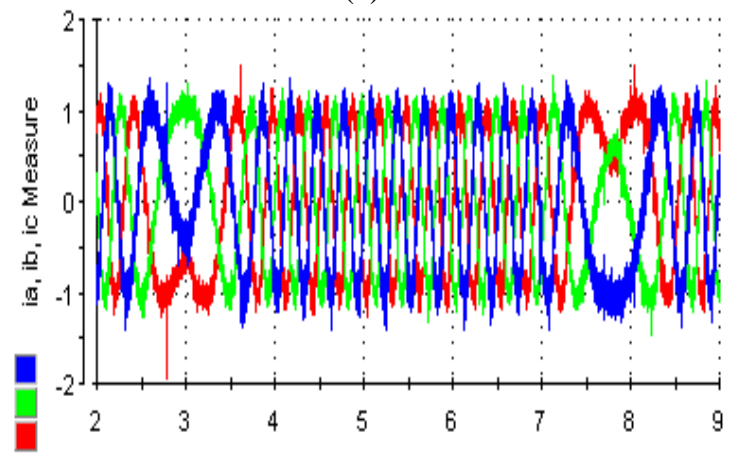

(c)

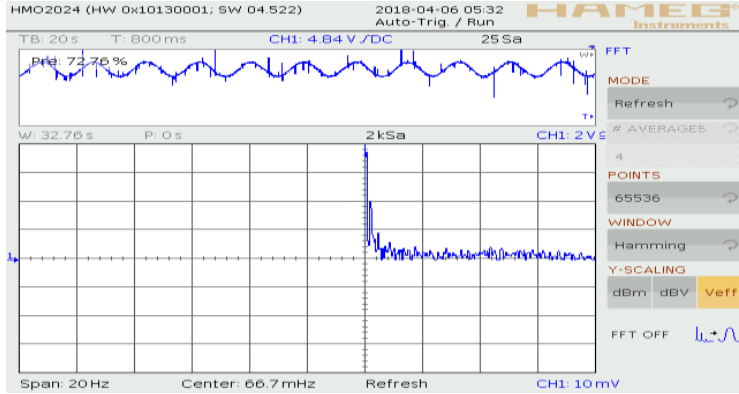

(e)

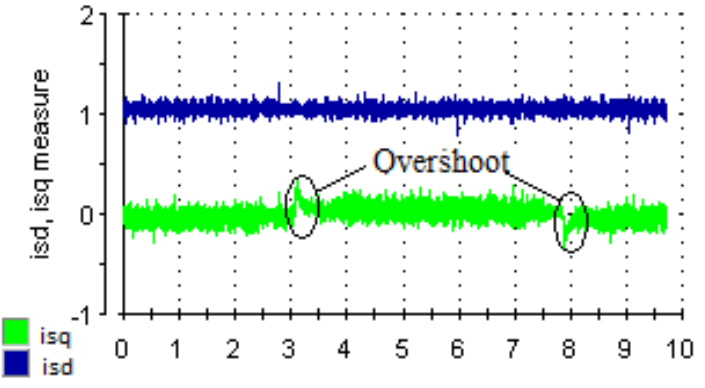

(b)

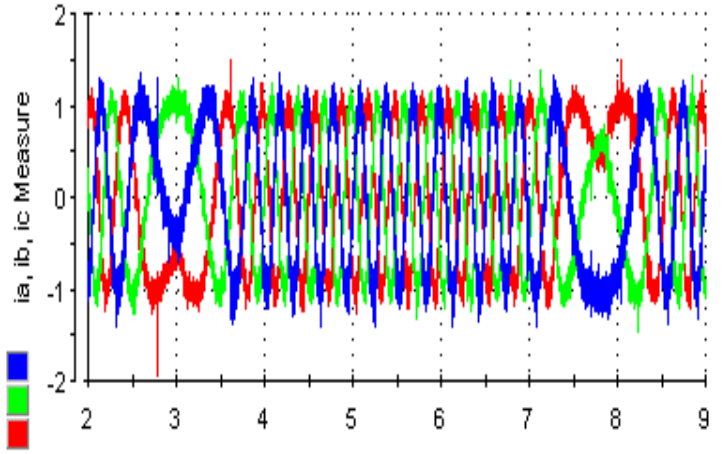

(d)

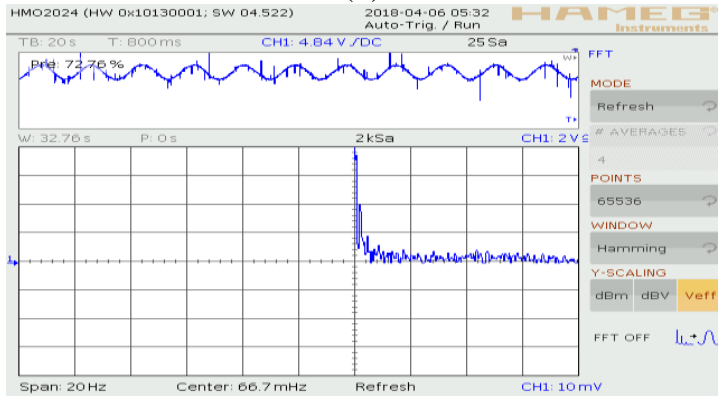

(f)

Figure 4. Stator current responses, (a) Stator current response using PCC-FOC, (b) Stator current response using PI-FOC, (c) 3 phase stator current response PCC-FOC, (d) 3 phase stator current response PI-FOC,

(e) Total harmonic distortion (THD\%) PCC-FOC, (f) Total harmonic distortion (THD\%) PI-FOC

From the result in Figure 4, the dynamic response evaluation stator current of controllers shows the setting time and overshoot and total hamonic distortion THD\% for both controllers are given in the Figure 5. The experimental results show its high performance. PCC reduces the system cost, shortens its response time and improves. Moreover, there is hardly any work for the cost function the general dynamics. It can be observed from numerical and experimental results that all two current controls have steady speed control performance, low torque ripples and fast response. However, PI current control than those of the PCC control. 


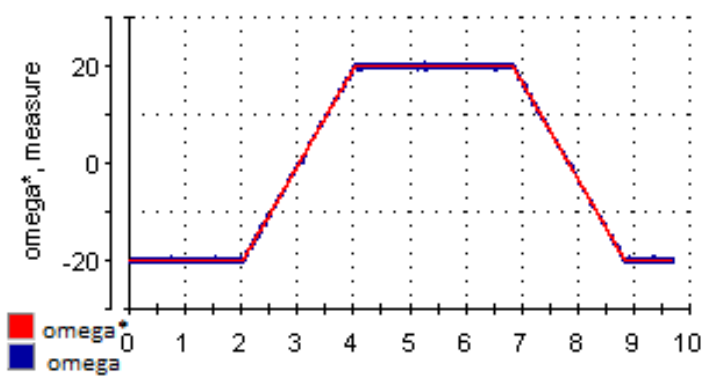

(a)

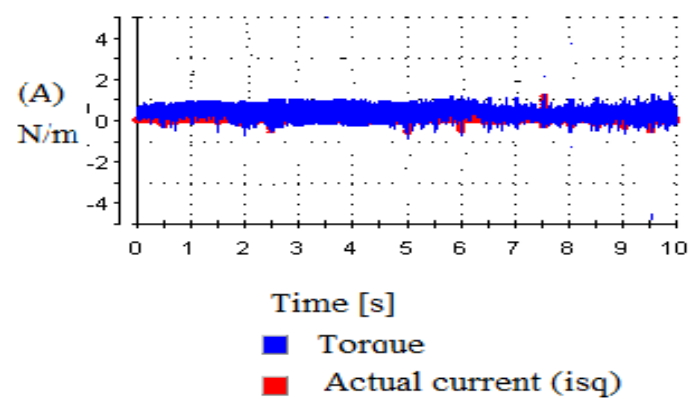

(c)

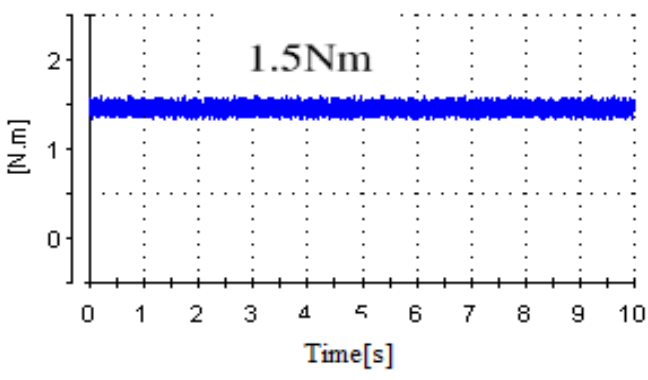

(e)

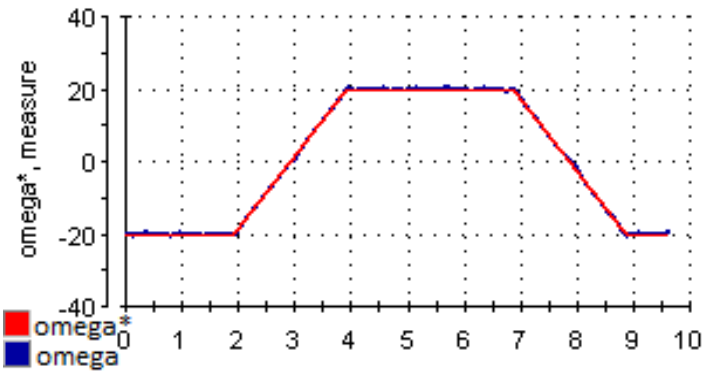

(b)

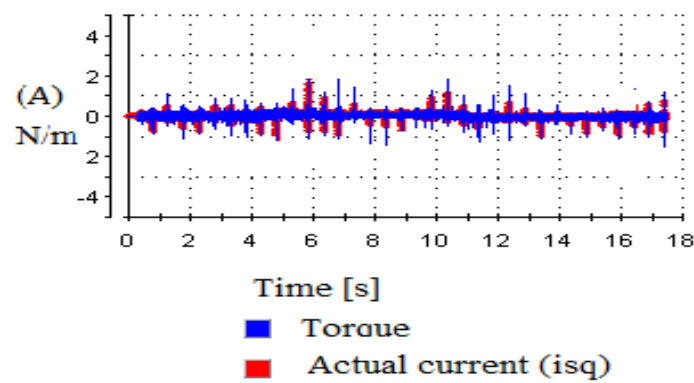

(d)

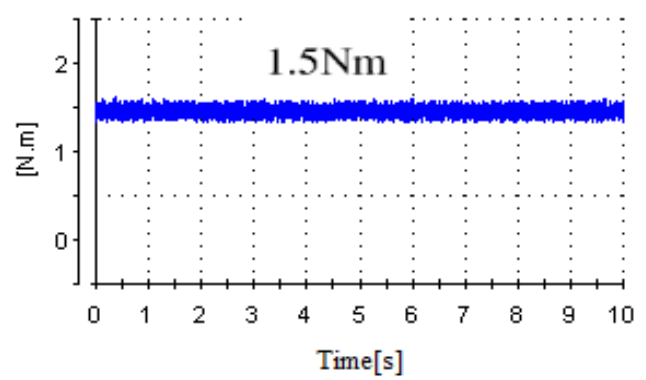

(f)

Figure 5. Torque and speed responses, (a) Speed response PCC-FOC, (b) Speed response PI-FOC,

(c) Torque response with no load PCC-FOC, (d) Torque response with no load PI-FOC, (e) Torque response with load PCC-FOC, (f) Torque response with load PI-FOC

\section{CONCLUSION}

In this paper, predictive current control of an induction machine fed by a two-level voltage source inverter model is proposed and the mathematical model of the predictive current is derived. By applying 8 switching states of voltage vectors, the one that produces the predictive current, closest to the reference current, is selected. The model is verified in experimental, and the results demonstrate the speed and electromagnetic torque of the motor have a good dynamic response for a wide speed range at both no load and loaded conditions. However, the ripple of electromagnetic torque is significant high. Further improvement needs to be done to reduce the ripple. And to promote all abilities to predict many states, the use of multi-level inverter migh be the proper choice and the should be further studied. On the other hand, the stator current control PI-FOC showed the stability of the settling.

\section{ACKNOWLEDGEMENTS} of Technology.

This research was supported by Research Foundation funded by Thai Nguyen University 


\section{REFERENCES}

[1] M. H. V. Reddy and V. Jegathesan, "Open loop V/f control of induction motor based on hybrid PWM with reduced torque ripple," 2011 International Conference on Emerging Trends in Electrical and Computer Technology, Nagercoil, pp. 331-336, 2011.

[2] P. Vas, "Vector control of AC machines," Oxford University Press, USA, 1990.

[3] J-A. Dittrich and P. Q. Nguyen, "Vector control of three-phase AC machines-system development in the practicesecond edition," Springer Berlin Heidelberg, 2015.

[4] J-K. Kang and S-K. Sul, "New direct torque control of induction motor for minimum torque ripple and constant switching frequency," IEEE Transactions on Industry Applications, vol. 35, no. 5, pp. 1076-1082, 1999.

[5] S. H. Asgari, M. Jannati, T. Sutikno, and N. R. N. Idris, "Vector control of three-phase induction motor with twostator phases open-circuit," International Journal of Power Electronics and Drive System, vol. 6, no. 2, pp. 282-292, June, 2015.

[6] N. H. Quang, N. P. Quang, N. N. Hien, and N. T. Binh, "Min max model predictive control for polysolenoid linear motor," International Journal of Power Electronics and Drive System, vol. 9, no. 4, pp. 1666-1675, 2018.

[7] N. H. Quang, N. P. Quang, D. T. Hai, and N. N. Hien, "On tracking control problem for polysolenoid motor model predictive approach," International Journal of Electrical and Computer Engineering, part II, vol. 10, no. 1, pp. 849-855, February 2020.

[8] N. H. Quang, N. P. Quang, D. P. Nam, and N. T. Binh, “ Multi parametric model predictive control based on laguerre model for permanent magnet linear synchronous motors," International Journal of Electrical and Computer Engineering, vol. 9, no. 2, pp. 1067-1077, April 2019.

[9] M. Bouziane and M. Abdelkader, "Direct space vector modulation for matrix converter fed dual star induction machine and neuro-fuzzy speed controller," Bulletin of Electrical Engineering and Informatics, vol. 8, no. 3, pp. 818-828, 2019.

[10] Y. Zahraoui, M. Akherraz, C. Fahassa, and S. Elbadaoui, "Induction motor harmonic reduction using space vector modulation algorithm," Bulletin of Electrical Engineering and Informatics, vol. 9, no. 2, pp. 452-465, 2020.

[11] K. A. Chinmaya and G. K. Singh, "Experimental analysis of various space vector pulse width modulation (SVPWM) techniques for dual three-phase induction motor drive," International Transactions on Electrical Energy Systems, vol. 29, no. 1, p. e2678, 2018.

[12] P. J. Patel, V. Patel, and P. N. Tekwani, "Pulse-based dead-time compensation method for self-balancing space vector pulse width-modulated scheme used in a three-level inverter-fed induction motor drive," IET Power Electronics, vol. 4, no. 6, pp. 624-631, 2011.

[13] H. R. Khoei and M. Zolfaghari, "New model reference adaptive system speed observer for field-oriented control induction motor drives using neural networks," Bulletin of Electrical Engineering and Informatics, vol. 5, no. 1, pp. 25-36, March 2016.

[14] L. Wang, S. Chai, D. Yoo, L. Gan, and K. Ng, "PID and predictive control of electrical drives and power converters using MATLAB/Simulink," John Wiley \& Sons, pp. 339-343, 2015.

[15] S. Kouro, P. Cortes, R. Vargas, U. Ammann, and J. Rodriguez, "Model predictive control-a simple and powerful method to control power converters," IEEE Transactions on Industrial Electronics, vol. 56, no. 6, pp. 1826-1838, June 2009.

[16] J. Rodriguez, M. P. Kazmierkowski, J. R.. Espinoza, P. Zanchetta, H. Abu-Rub, H. A. Young, and C. A. Rojas, "State of the art of finite control set model predictive control in power electronics," IEEE Transactions on Industrial Informatics, vol. 9, no. 2, pp. 1003-1016, May 2013.

[17] L. Wu and X. Mei, "Predictive current control of an induction machine fed by a two-level voltage source inverter," HAL-01527733 version 1, pp. 1-7, 2017.

[18] J. Rodriguez, J. pontt, C. A. Silva, P. Correa, P. Lezana, P. Cortes, and U. Ammann, "Predictive current control of a voltage source inverter," IEEE Transactions on Industrial Electronics, vol. 54, no. 1, pp. 495-503, Feb. 2007.

[19] E. Zafra, S. Varquez, H. G. Miranda, J. A. Sanchez, A. Marquez, J. I Leon, and L. G. Franquelo, "Efficient FPSoC prototyping of FCS-MPC for three-phase voltage source inverters," Energies, vol. 13, no. 5, pp. 1-16, 2020.

[20] T. Geyer, G. Papafotiou, and M. Morari, "Model predictive direct torque control-Part I: Concept, algorithm, and analysis," IEEE Transactions on Industrial Electronics, vol. 56, no. 6, pp. 1894-1905, June 2009.

[21] F. Barrero, J. Prieto, W. Levi, R. Gregor, S. Toral, M. J. Duran, and M. Jones, "An enhanced predictive current control method for asymmetrical six-phase motor drives," IEEE Transactions on Industrial Electronics, vol. 58, no. 8, pp. 3242-3252, Aug. 2011.

[22] F. Wang, Z. Zhang, S. A. Davari, R, Fotouhi, D. A. Khaburi, J. Rodriguez, and R. Kennel, “An encoderless predictive torque control for an induction machine with a revised prediction model and EFOSMO," IEEE Transactions on Industrial Electronics, vol. 61, no. 12, pp. 6635-6644, Dec. 2014.

[23] R. Gunabalan and V. Subbiah, "Speed sensorless vector control of induction motor drive with PI and fuzzy controller," International Journal of Power Electronics and Drive System, vol. 5, no. 3, pp. 315-325, 2015.

[24] M. Zair and A. Hazzab, "MRAS speed sensorless vector control of induction motor drives using predictive adaptation mechanism," International Journal of Power Electronics and Drive System, vol. 9, no. 4, pp. 1523-1533, 2018.

[25] N. P. Quang, V. T. Ha, and T. V. Trung, "A new control design with dead-beat behavior for stator current vector in three-phase AC drives," International Journal of Electrical and Electronics Engineering, vol. 5, no. 4, p. 1-8, 2018. 